\title{
Improvements in Cervical Spinal Canal Diameter and Neck Disability Following Correction of Cervical Lordosis and Cervical Spondylolistheses Using Chiropractic BioPhysics Technique: A Case Series
}

\author{
Curtis Fedorchuk ${ }^{1 *}$, Douglas Frank Lightstone ${ }^{1}$, Robert DeVon Comer ${ }^{1}$, Evan Katz ${ }^{2}$, Justin Wilcox ${ }^{3}$ \\ 1. Institute for Spinal Health and Performance, Cumming, GA, USA
}

2. Private Practice, Katz Chiropractic and Rehabilitation Clinic, Boulder, CO, USA

3. Private Practice, Bayside Spine and Sport, San Diego, CA, USA

* Correspondence: Curtis Fedorchuk, D.C., 460 Brannon Rd, Suite 101, Cumming, GA 30041, USA

( $\triangle$ cfedorchuk@comcast.net)

Radiology Case. 2020 Apr; 14(4):21-37 :: DOI: 10.3941/jrcr.v14i4.3890

\begin{abstract}
Cervical spondylolisthesis indicates instability of the spine and can lead to pain, radiculopathy, myelopathy and vertebral artery stenosis. Currently degenerative cervical spondylolisthesis is a wait-and-watch condition with no treatment guidelines. A literature review and discussion will be provided. 8 females presented with neck pain, disability, and history of motor vehicle collision. Radiographs revealed abnormal cervical alignment, spinal canal narrowing, and spondylolistheses. After 30 sessions of Chiropractic BioPhysics ${ }^{\circledR}$ care over 12 weeks, patients reported improved symptoms and disabilities. Radiographs revealed improvements in cervical alignment, spondylolistheses, and spinal canal diameter. Motor vehicle collision may cause instability and abnormal alignment of the cervical spine leading to cervical spondylolisthesis. Improving spinal alignment may be an effective treatment to reduce vertebral subluxation and cervical spondylolistheses and improve neck disability as a result of improved spinal alignment.
\end{abstract}

\section{CASE SERIES}

\section{CASE SERIES}

\section{INTRODUCTION}

Spondylolisthesis refers to the slippage of one vertebral body on the vertebra below. It is considered uncommon in the cervical spine when compared to the lumbar spine and is now being recognized as an under-studied condition [1].

The two main types are congenital and acquired spondylolisthesis. Congenital spondylolisthesis is caused by a failure of formation of facet joint in the vertebrae and acquired spondylolisthesis refers to a defect in the pars interarticularis caused by degeneration, trauma, pathology, or surgery [2]. Degenerative cervical spondylolisthesis (DCS) is categorized into 3 different categories dependent on radiographic features, symptoms, and morphology. Each type has a suggested surgical procedure. Stage 1 presents with pain and noticeable facet joint degeneration; surgical recommendations include single level discectomy, repositioning, and fusion. Stage 2 patients will present with radiculopathy or myelopathy with 
facet degeneration and vertebral body degeneration; surgical recommendations include a multi-level discectomy, repositioning, and fusion. Stage 3 patients are identified with severe myelopathy and spinal deformity; surgical recommendations include corpectomy along with fusion of adjacent segments $[1,3,4]$. As of 2020, there are no current medical guidelines to follow. Surgery is indicated when the patient's symptoms continually worsen and there is a proven instability or spinal cord compression [5].

DCS prevalence is estimated to be $5.2 \%$ to $11 \%$ of the population and is understudied in comparison to the more common lumbar spondylolisthesis. The male-to-female ratio is 1.5 to 1 in grade 1 and 2.2 to 1 in grade 2 spondylolisthesis and there is an increased prevalence after 60 years with a $33.3 \%$ prevalence in 20 to 59 years and $66.7 \%$ in 60 to 99 years of age [6]. DCS in symptomatic patients was found to be $16.4 \%$ prevalence of grade 1 and $3.4 \%$ of grade 2 (Table 2). DCS was graded and defined by the following criteria. Grade 1 is defined as $2-3 \mathrm{~mm}$ of displacement and grade 2 is defined as displacement greater than $3 \mathrm{~mm}[1,7]$.

When left untreated, DCS can lead to pain, radiculopathy, myelopathy and vertebral artery stenosis $[1,5]$. DCS is also an indicator of cervical vertebrae instability. This is associated with disc degeneration and facet joint arthropathy [8]. C3-C5 disc levels are the most common levels of DCS.

The natural progression of spondylolisthesis is monitored by radiograph. Currently the literature only shows resolution of non-operative spondylosis in patients with unilateral lesions $[2,9]$. The progression of the spondylolisthesis includes many variables, but age seems to play a large role [9].

The objective of this case series is to report on the structural, functional, and symptomatic improvements in eight patients with cervical spondylolistheses using Chiropractic BioPhysics ${ }^{\circledR}(\mathrm{CBP} \circledast)$. CBP $®$ technique has established a valid healthy, normal, ideal spine model. $\mathrm{CBP} \circledast$ has developed valid, reliable examination and assessment methods for spinal posture, alignment, and biomechanics. Chiropractic BioPhysics ${ }^{\circledR}$ has established effective, reproducible treatment methods for spinal correction that have been tested and shown to be effective and superior to various other treatment methods in randomized and non-randomized clinical trials. CBP® does this by normalizing spinal posture, alignment, and biomechanics by applying Mirror Image ${ }^{\circledR}$ exercises, adjustments, traction which, in turn, addresses altered musculature, neurology, and connective tissue, respectively [10]. Mirror Image $®$ exercises strengthen weak musculature and lengthen tight musculature that have adapted to unhealthy posture to correct and maintain corrections in spinal alignment and postural abnormalities. Mirror Image ${ }^{\circledR}$ adjusting stimulates mechanoreceptors and proprioceptors to retrain the body's central nervous system (CNS) to adapt to normal, healthy posture. Mirror Image ${ }^{\circledR}$ traction allows for viscoelastic deformation of spinal ligaments and corrects the patient's abnormal posture by initiating muscle and ligament creep creating permanent restorative change [10].

\section{CASE DESCRIPTIONS}

\section{Patients}

Eight female patients with a mean age of $53.4 \pm 9.1$ years presented with a chief complaint neck pain (NP), bilateral upper trapezii pain, neck stiffness, restricted cervical range of motion (ROM), and radicular symptoms into the shoulder(s) and(or) $\operatorname{arm}(\mathrm{s})$. The patients reported limitations in performing activities of daily living (ADL). The patients reported a mean score of $34.5 \pm 5.7 \%$ on the self-rating neck disability index (NDI) outcome assessment indicating a mean moderate neck disability $[11,12]$. The NDI is a patient-reported questionnaire that determines the disability effect of neck pain on a person's daily life. There are ten questions in the following categories: Pain Intensity, Personal Care, Lifting, Reading, Headaches, Concentration, Work, Driving, Sleeping, and Recreation. There are six answer choices for each question. The answers are scored from 0 (no disability) to 5 (complete disability). The ten scores are totaled, multiplied by two, and are reported from 0-100 often as a percentage (0-100\%). "The Neck Disability Index has been used in over 300 publications, translated into 22 languages....and endorsed for use by a number of clinical practice guideline committees...making it the most widely used and most strongly validated instrument for assessing suffering disability in patients with neck pain" [12]. The patients had a history of a motor vehicle collision (MVC). The patients reported that they sought medical treatment and(or) physical therapy greater than 6 months prior to chiropractic care and that their symptoms had not resolved prior to chiropractic care.

Patients were selected from a records review from two chiropractic clinics with advanced training in corrective chiropractic care and that follow $\mathrm{CBP} ®$ protocols [10]. The patients selected for this case series met certain inclusion criteria. All patients presented with neck pain and disability, a history of motor vehicle collision trauma, and DCS as diagnosed by radiographic analysis. All patients completed a recommended 30 visits which included chiropractic adjustments, exercise, and traction over 12 weeks of corrective chiropractic care with post-treatment radiographs for comparison to pre-treatment radiographs. Patients were excluded from this case series if they had red flags or contraindications for chiropractic adjustments, exercise, or traction to the cervical spine, cervical or cervicothoracic scoliosis, or lateral translations of the head resulting in $7 \mathrm{~mm}$ or greater lateral displacement of the second cervical vertebra (C2) with respect to the fourth thoracic vertebra (T4) [13].

\section{Radiographic Analysis}

Spinal radiographs are necessary to assess for red flags or contraindications to spinal treatment, pathology, spinal alignment, and vertebral subluxations, such as cervical spondylolisthesis, to determine specific approaches to structural spinal rehabilitation as well as patient progress in a spinal correction plan [14]. The Harrison posterior tangent method provides measurements of regional and intersegmental vertebral angles and regional and intersegmental vertebral translations. Cervical angles are measured by drawing a line tangent to the posterior margin of each vertebral body from C2 to the seventh cervical vertebra (C7). Measurements of a 
spinal region provide the absolute rotation angle (ARA). Regional anteroposterior (AP) spinal translations can be measured by drawing a vertical line from an inferior landmark and measuring the horizontal displacement to a superior landmark. AP translation of the cervical spine is measured using the posterior, inferior body of $\mathrm{C} 7$ as the inferior landmark and the posterior, superior body of $\mathrm{C} 2$ as the superior landmark. Intersegmental AP translations are determined by measuring the distance perpendicular to the posterior tangent line of the inferior vertebra to the posterior, inferior aspect of the superior vertebra. Spinal canal diameter (SCD) on radiograph is measured from the closest points between the posterior aspect of a vertebra and the spinolaminar line of adjacent vertebrae. For example, if $\mathrm{C} 2$ slips anterior to $\mathrm{C} 3$, the SCD would be measured from the inferior end of the spinolaminar line of $\mathrm{C} 2$ to the posterosuperior corner of $\mathrm{C} 3$. And if $\mathrm{C} 2$ slips posterior to $\mathrm{C} 3$, the SCD would be measured from the posteroinferior corner of $\mathrm{C} 2$ to the superior end of the spinolaminar line of C3 [15].

The spinal postural and radiographic analysis uses a righthand, thumb-up Cartesian coordinate system to illustrate translations in the coronal, sagittal, and transverse planes and rotations around $\mathrm{x}, \mathrm{y}$, and $\mathrm{z}$-axes of the head, thorax, and pelvis [10]. In documenting spinal positioning, the positive or negative sign indicates the direction of translation in or rotation around the $\mathrm{x}, \mathrm{y}$, and $\mathrm{z}$-axes in the frontal, sagittal, and horizontal planes. The first letter indicates translation $(\mathrm{T})$ or rotation $(\mathrm{R})$. The second letter indicates the axis in or around which the $\mathrm{T}$ or $\mathrm{R}$ takes place. The third letter indicates head $(\mathrm{H})$, thorax $(\mathrm{T})$, or pelvis $(\mathrm{P})$ with respect to the body region below. The head is relative to the thorax; the thorax is relative to the pelvis; and the pelvis is relative to the feet. Vertebra then denote the anatomical landmarks involved [10].

Neutral lateral cervical (NLC) radiographs were analyzed using PostureRay® Electronic Medical Records (EMR) Software (PostureCo, Inc., Trinity, FL, USA) per the Harrison Posterior Tangent method for spine views in the sagittal place [16-18]. These examination and analysis methods are valid [19-23], reliable, and repeatable [16-20,24], as is posture [19].

Initial NLC view revealed a mean forward head posture (Tz C2-C7) of $15.1 \pm 9.3 \mathrm{~mm}$ (ideal is $0.0 \mathrm{~mm}$ and average is $15 \mathrm{~mm}$ ), mean absolute rotational angle from $\mathrm{C} 2$ to $\mathrm{C} 7$ (ARA $\mathrm{C} 2-\mathrm{C} 7$ ) of $-15.5 \pm 15.8^{\circ}$ (normal is $-42.0^{\circ}$ and average is $34^{\circ}$ ), DCS at 17 intersegmental locations with a mean horizontal displacement (Tz DCS) of $3.1 \pm 0.9 \mathrm{~mm}$ (as high as $4.5 \mathrm{~mm}$ ), and a mean SCD at corresponding DCS locations of $14.8 \pm 0.6$ $\mathrm{mm}$ (normal is $17.0 \mathrm{~mm}$ ) (Figures 1a-8a, Table 1) [3]. AP horizontal displacement of one vertebra on another results in a narrowing of the spinal canal as the spinolaminar line of the vertebra more anterior approximates to the posterior vertebral line of the vertebra more posterior as seen on sagittal spinal radiographs and can result in spinal canal stenosis as shown in the mean values of the Table 1.

All patients who met the inclusion criteria had an abnormal ARA C2-C7 consistent with MVC trauma as determined by radiographic examination and analysis.

\section{Interventions and Outcomes}

The patients completed 30 sessions of Mirror Image ${ }^{\circledR}$ spinal exercises, adjustments, and traction over 12 weeks per CBP® protocols [10]. The Mirror Image ${ }^{\circledR}$ exercise involved the patient performing the following steps:

\section{Maximum anterior head translation $(+T z H)$}

Anterior head translation causes a coupling pattern of the cervical spine that causes lordosis of the upper cervical spine and kyphosis (reversal of curve) of the lower cervical spine.

2. While maintaining $+T_{z} H$, maximum head extension $(-R x H)$ Maintenance of the anterior head translation allows for the upper cervical spine to maintain its lordosis and maximum head extension allows for the lower cervical spine to move toward a healthy lordotic curve.

3. While maintaining the $-\mathrm{RxH}$, posterior head translation ($\left.T_{z} H\right)$

The posterior head translation from this position allows for the head to return to a normal postural position while maintaining the induced cervical lordosis from previous movements.

The patient held the final position for 10 seconds before relaxing and repeating for 20 repetitions. Mirror Image $\AA$ exercises strengthen weak musculature and lengthen tight musculature that have adapted to unhealthy posture to correct and maintain corrections in spinal alignment and postural abnormalities [10]. Mirror Image $®$ adjustments involved using an OMNI elevation adjusting table with sectional dropmechanisms and setting up the patient in the position obtained during Mirror Image ${ }^{\circledR}$ exercise followed thrust to the midlower cervical vertebrae. The Impulse ${ }^{\circledR}$ adjusting instrument (Neuromechanical Innovations, Chandler, AZ, USA) was also used for Mirror Image ${ }$ adjustments. Mirror Image ${ }^{\circledR}$ adjusting stimulates mechanoreceptors and proprioceptors to retrain the body's CNS to adapt to normal, healthy posture [10]. Mirror Image ${ }^{\circledR}$ traction was performed using a Universal Tractioning Systems (UTS) Total Spine unit (Universal Tractioning Systems, Inc., Las Vegas, NV, USA). A force combining $+\mathrm{TyH}$ and $-\mathrm{TzH}$ was applied using a chin-occiput harness and $+\mathrm{TzH}$ was applied to the mid-cervical vertebra for periods starting at 4 minutes and increasing by 2 minutes with each visit until 15 minutes was reached. Mirror Image ${ }^{\circledR}$ traction allows for viscoelastic plastic deformation of spinal ligaments [10] and corrects the patient's abnormal posture by initiating muscle and ligament creep creating permanent restorative change [25].

\section{Re-Exam Findings}

After 30 sessions over 12 weeks, the patients reported a mean improvement from $34.5 \%$ to $4.3 \%$ on the self-rating NDI outcome assessment indicating improvement from moderate to minimal neck disability. Post-treatment NLC radiographs (Figures 1b-8b) were taken and compared with the pre-treatment assessments (Table 1). The re-exam NLC radiographs revealed that mean $+\mathrm{TzH}$ improved $3.3 \mathrm{~mm}$ from $15.1 \mathrm{~mm}$ to $11.8 \mathrm{~mm}$ and mean ARA C2-C7 improved $6.6^{\circ}$ from $-15.5^{\circ}$ to $-22.1^{\circ}$. Mean horizontal translations at DCS locations improved $2.6 \mathrm{~mm}$ from $3.1 \mathrm{~mm}$ to $0.5 \mathrm{~mm}$ 
(Table 1). Mean SCD at DCS locations improved $2.2 \mathrm{~mm}$ from $14.8 \mathrm{~mm}$ to $17.0 \mathrm{~mm}$.

\section{DISCUSSION}

\section{Chiropractic Management}

There is a lack of evidence reporting on the effects of chiropractic management of DCS and almost all studies focus on the reduction of symptoms with no measured reduction of spondylolisthesis. There is only one case published by Fedorchuk, Lightstone, and Cohen that shows both reduction in symptoms and reduction of spondylolisthesis measurements [26].

Fedorchuk, Lightstone, and Cohen presented a case of 52year-old female with severe neck pain, neck stiffness, thoracic pain, and lower neck swelling [26]. She denied a history of trauma. As per $\mathrm{CBP} \AA$ protocol, cervical radiographs were taken before chiropractic care. Findings included anterior translations at C4-C5 $2.4 \mathrm{~mm}, \mathrm{C} 6-\mathrm{C} 70.6 \mathrm{~mm}$, and C7-T1 1.4 $\mathrm{mm}$. In addition to posterior translations at $\mathrm{C} 2-\mathrm{C} 32.0 \mathrm{~mm}$, C3-C4 $1.3 \mathrm{~mm}$, and C5-C6 $2.2 \mathrm{~mm}$. There was an anterior head translation of $19.66 \mathrm{~mm}$ and an ARA C2-C7 of $-22.8^{\circ}$ (ideal is $-42^{\circ}$ and average is $34.0^{\circ}$ ). Chiropractic treatment included spinal manipulative therapy and Mirror Image ${ }^{\circledR}$ adjustments, traction using the Denneroll ${ }^{\mathrm{TM}}$ spinal orthotic, and exercises [26]. Post -treatment radiographs showed a reduction of anterior translations at $\mathrm{C} 4-\mathrm{C} 5$ of $1.7 \mathrm{~mm}, \mathrm{C} 6-\mathrm{C} 7$ of $0.9 \mathrm{~mm}$, and $\mathrm{C} 7-\mathrm{T} 1$ was reduced $1.3 \mathrm{~mm}$. Posterior translation reduced at $\mathrm{C} 2-\mathrm{C} 31.1 \mathrm{~mm}, \mathrm{C} 3-\mathrm{C} 40.5 \mathrm{~mm}$, and C5C6 $1.5 \mathrm{~mm}$. The anterior head translation reduced from 19.6 to $9.0 \mathrm{~mm}$, and the ARA C2-C7 improved from $-22.8^{\circ}$ to $-26^{\circ}$. The patient also reported a resolution in her neck pain, stiffness, tension, and swelling [26].

\section{Spinal Alignment and Posture}

Prevalence of DCS may be more common than previously thought [1]. DCS has been showed to be caused by sagittal cervical curve mal-alignment, facet joint angles, disc degeneration, and facet joint arthrosis all altering biomechanics which lead to increased stress with flexion and extension and may damage the disc and ligaments allowing for the slippage to occur [8].

There are many proposed mechanisms of DCS. Woiciechowsky proposes the idea that instability will cause the damage to the ligaments and the disc causing the vertebral body to horizontally displace [8]. Most of the time, neck pain is the first symptom and is experienced before facet and disc degeneration take place [8]. If patients with neck pain are evaluated for instability before there is damage to the facet joints, ligaments, and discs, degenerative cervical spondylolisthesis may be slowed or prevented.

Jun et al. showed that congenital anatomy has influence over the sagittal lordosis of the cervical spine [27]. T1 slope angle has a direct influence over the prevalence of DCS. Jun et al. theorized that $\mathrm{T} 1$ slope is an important factor in the sagittal cervical alignment, which will cause anterior translation of the body's center of gravity leading to disc degeneration and collapse accelerated by arthrosis in the posterior facets [27]. Hypermobility, sliding force, and loss of cervical lordosis cause stress at the disc and facet joints especially in the midcervical region which accounts for the higher prevalence of the DCS in the mid-cervical spine [27].

Degenerative changes in the cervical spine has been shown been shown to increase as the cervical sagittal alignment is altered. It is well documented in the literature that cervical lordosis is associated with nerve entrapment, pain, and degeneration of the cervical spine [28].

\section{Differential Diagnosis}

The differential diagnosis for DCS include cervical fracture, cervical canal stenosis, cervical disc degeneration, and cervical facet dislocation or arthropathy [3]. These conditions often present with the similar clinical symptoms, such as neck pain and radiculopathy. However, cervical spondylolisthesis is often made worse with extension and can be asymptomatic (Table 2) [3].

\section{Strengths and Limitations}

This case series provides a clear objective and welldefined protocol. This case series is not randomized or blinded which lends itself to selection bias. However, this case series provides explicit inclusion and exclusion criteria and consecutive patient selection. This helps to limit selection bias. Additionally, this case series includes objective and subjective clinically relevant outcomes with valid and reliable quantified measurements. This helps to strengthen the value of the series.

This case series is retrospective and contains a small number of participants $(n=8)$ which limit its generalizability to larger populations of patients.

\section{CONCLUSION}

Currently DCS is a wait-and-watch condition with no treatment guidelines. $\mathrm{CBP} \otimes$ focuses on restoring healthy alignment and biomechanics of the spine and posture [10]. This case series would have benefited from magnetic resonance imaging (MRI) of the cervical spine to determine any soft tissue damage as well as spinal cord compression and canal stenosis. Computed Tomography (CT) of the cervical spine can show a more accurate slippage measurement of the vertebrae before and after treatment.

In this case series, all patients who met the inclusion criteria had an abnormal ARA C2-C7 with buckling of the cervical spine consistent with MVC trauma as determined by radiographic examination and analysis. Motor vehicle trauma may cause a buckling effect to the cervical spine and damage to the ligaments of the cervical spine leading to instability and abnormal cervical alignment that culminate in degenerative cervical spondylolisthesis. 
This case series shows that $\mathrm{CBP} \circledast$ spinal rehabilitation may be an effective conservative, non-surgical treatment for DCS and associated symptoms including neck pain and cervical radiculopathy. By using $\mathrm{CBP} \circledast$ spinal rehabilitation to improve spinal alignment and postural distortions, the need for medical or invasive surgical procedures may be negated. Future prospective studies involving larger populations, multiple clinic sites, controlled and experimental groups, and long-term follow-ups, will shed more light on the effectiveness and reliability of $\mathrm{CBP} \AA$ in correcting cervical spondylolisthesis and the associated functional and symptomatic effects and pathologies.

\section{TEACHING POINT}

Multiple cervical degenerative spondylolistheses with up to $4.5 \mathrm{~mm}$ of horizontal displacement may be reduced or corrected by using corrective spinal rehabilitation. By using corrective spinal rehabilitation to improve sagittal spinal alignment and posture, the need for medical or invasive surgical procedures may be negated for patients with symptomatic severe and moderate degenerative cervical spondylolisthesis.

\section{REFERENCES}

1. Suzuki A, Daubs MD, Inoue $\mathrm{H}$, et al. Prevalence and motion characteristics of degenerative cervical spondylolisthesis in the symptomatic adult. Spine (Phila $\mathrm{Pa}$ 1976). 2013;38(17):E1115-20. PMID: 23680839.

2. Sedney CL, Mcconda DB, Daffner SD. Natural history of spondylolysis and spondylolisthesis. Semin Spine Surg. 2014;26(4):214-218.

3. Jiang SD, Jiang LS, Dai LY. Degenerative cervical spondylolisthesis: a systematic review. Int Orthop. 2011;35(6):869-75. PMID: 21264670.

4. Lee C, Woodring JH, Rogers LF, Kim KS. The radiographic distinction of degenerative slippage (spondylolisthesis and retrolisthesis) from traumatic slippage of the cervical spine. Skeletal Radiol. 1986;15(6):439-43. PMID: 3764470.

5. McTimoney CA, Micheli LJ. Current evaluation and management of spondylolysis and spondylolisthesis. Curr Sports Med Rep. 2003;2(1):41-6. PMID: 12831675.

6. Kopacz KJ, Connolly PJ. The prevalence of cervical spondylolisthesis. Orthopedics. 1999 Jul;22(7):677-9. PMID: 10418863

7. Ward CV, Latimer B. Human evolution and the development of spondylolysis. Spine (Phila Pa 1976). 2005;30(16):1808-14. PMID: 16103848.

8. Woiciechowsky C, Thomale UW, Kroppenstedt SN. Degenerative spondylolisthesis of the cervical spine-- symptoms and surgical strategies depending on disease progress. Eur Spine J. 2004;13(8):680-4. PubMed PMID: 15221569.

9. Park MS, Moon SH, Lee HM, et al. The natural history of degenerative spondylolisthesis of the cervical spine with 2- to 7-year follow-up. Spine (Phila Pa 1976). 2013;38(4):E205-10. PMID: 23169076.

10. Oakley PA, Harrison DD, Harrison DE, Haas JW. Evidence-based protocol for structural rehabilitation of the spine and posture: review of clinical biomechanics of posture (CBP) publications. J Can Chiropr Assoc. 2005;49(4):270-96. PMID: 17549209.

11. Vernon H, Mior S. The Neck Disability Index: a study of reliability and validity. J Manipulative Physiol Ther. 1991 Sep;14(7):409-15.

12. MacDermid JC, Walton DM, Avery S, et al. Measurement properties of the neck disability index: a systematic review. J Orthop Sports Phys Ther. 2009;39(5):400-17. PMID: 19521015.

13. Harrison DE, Cailliet R, Betz J, Haas JW, Harrison DD, Janik TJ, Holland B. Conservative methods for reducing lateral translation postures of the head: a nonrandomized clinical control trial. J Rehabil Res Dev. 2004;41(4):631-9. PMID: 15558391.

14. Oakley PA, Cuttler JM, Harrison DE. X-Ray Imaging is Essential for Contemporary Chiropractic and Manual Therapy Spinal Rehabilitation: Radiography Increases Benefits and Reduces Risks. Dose Response. 2018;16(2):1-7. PMID: 29977177.

15. Ivancic PC. Cervical neural space narrowing during simulated rear crashes with anti-whiplash systems. Eur Spine J. 201;21(5):879-86. PMID: 22270248.

16. Jackson BL, Harrison DD, Robertson GA, Barker WF. Chiropractic biophysics lateral cervical film analysis reliability. J Manipulative Physiol Ther. 1993;16(6):384-91. PMID: 8409786.

17. Harrison DE, Harrison DD, Cailliet R, Troyanovich SJ, Janik TJ, Holland B. Cobb method or Harrison posterior tangent method: which to choose for lateral cervical radiographic analysis. Spine (Phila $\mathrm{Pa}$ 1976). 2000;25(16):2072-8. PMID: 10954638.

18. Harrison DE, Holland B, Harrison DD, Janik TJ. Further reliability analysis of the Harrison radiographic line-drawing methods: crossed ICCs for lateral posterior tangents and modified Risser-Ferguson method on AP views. J Manipulative Physiol Ther. 2002;25(2):93-8. PMID: 11896376.

19. Harrison DE, Harrison DD, Colloca CJ, Betz J, Janik TJ, Holland B. Repeatability over time of posture, radiograph positioning, and radiograph line drawing: an analysis of six control groups. J Manipulative Physiol Ther. 2003;26(2):8798. PMID: 12584507. 
20. Harrison DD, Janik TJ, Troyanovich SJ, Holland B. Comparisons of lordotic cervical spine curvatures to a theoretical ideal model of the static sagittal cervical spine. Spine (Phila Pa 1976). 1996;21(6):667-75. PMID: 8882687.

21. Harrison DD, Janik TJ, Troyanovich SJ, Harrison DE, Colloca CJ. Evaluation of the assumptions used to derive an ideal normal cervical spine model. J Manipulative Physiol Ther. 1997;20(4):246-56. PMID: 9168409.

22. Harrison DD, Harrison DE, Janik TJ, et al. Modeling of the sagittal cervical spine as a method to discriminate hypolordosis: results of elliptical and circular modeling in 72 asymptomatic subjects, 52 acute neck pain subjects, and 70 chronic neck pain subjects. Spine (Phila $\mathrm{Pa}$ 1976). 2004;29(22):2485-92. PMID: 15543059.

23. McAviney J, Schulz D, Bock R, Harrison DE, Holland B. Determining the relationship between cervical lordosis and neck complaints. J Manipulative Physiol Ther. 2005;28(3):187-93. PMID: 15855907.

24. Troyanovich SJ, Harrison D, Harrison DD, Harrison SO, Janik T, Holland B. Chiropractic biophysics digitized radiographic mensuration analysis of the anteroposterior cervicothoracic view: a reliability study. J Manipulative Physiol Ther. 2000;23(7):476-82. PMID: 11004652.

25. Fedorchuk C, Opitz K. Improvement in quality of life and improved cervical curve in an 11-year old child with asthma following chiropractic intervention: A case study. J Pediatr Matern \& Fam Health - Chiropr. 2014;2014(2):37-46.

26. Fedorchuk C, Lightstone D, Cohen M. Reduction in Cervical Anterolisthesis \& Pain in a 52-Year-Old Female Using Chiropractic BioPhysics® Technique: A Case Study and Selective Review of Literature. Ann Vert Sublux Res. 2016;2016(3):118-24.

27. Jun HS, Kim JH, Ahn JH, Chang IB, Song JH, Kim TH, Park MS, Kim YC, Kim SW, Oh JK. T1 slope and degenerative cervical spondylolisthesis. Spine (Phila Pa 1976). 2015;40(4):E220-6. PMID: 25423304.

28. Okada E, Matsumoto M, Ichihara D, et al. Does the sagittal alignment of the cervical spine have an impact on disk degeneration? Minimum 10-year follow-up of asymptomatic volunteers. Eur Spine J. 2009;18(11):1644-51. PMID: 19609784. 


\section{FIGURES}

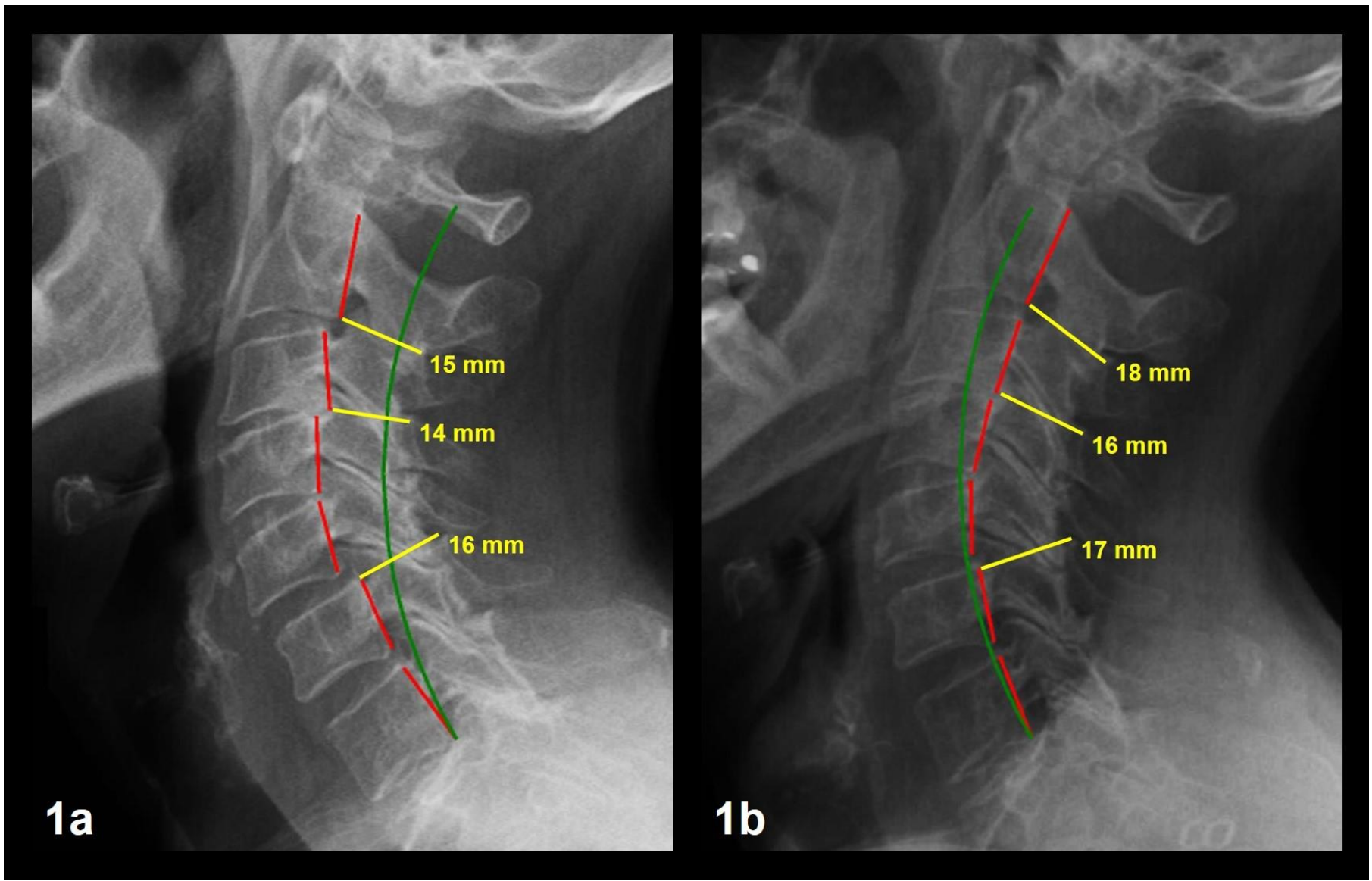

Figure 1: 63-year-old female with NP, bilateral upper trapezii pain, neck stiffness, restricted cervical ROM, cervical radicular symptoms, and a history of motor vehicle collision trauma.

Image Features: The green line represents a normal, ideal cervical alignment. The red line represents the actual posterior tangent lines of the $\mathrm{C} 2-\mathrm{C} 7$ vertebrae. The yellow line and text represent the spinal canal diameters and measurements at spondylolisthesis locations.

Figure 1a Patient 1 Pre-Treatment NLC Radiograph

1a Findings: NLC image shows Tz C2-C7 of $17.4 \mathrm{~mm}$, ARA C2-C7 of $-50.6^{\circ}$, spondylolistheses at C2-C3, C3-C4, and C5-C6 with $\mathrm{Tz}$ measurements of $-3.5 \mathrm{~mm},-2.7 \mathrm{~mm}$, and $2.6 \mathrm{~mm}$, respectively. Tz SCD at C2-C3, C3-C4, and C5-C6 measure 15, 14, and $16 \mathrm{~mm}$, respectively.

Technique: $30 \mathrm{mAs}, 200 \mathrm{~mA}, 76 \mathrm{kVp}, 72 " \mathrm{FFD}, \mathrm{CR}$ at C4.

Figure 1b Patient 1 Post-Treatment NLC Radiograph Intervention: Chiropractic BioPhysics ${ }^{\circledR}$ Mirror Image ${ }^{\circledR}$ spinal adjustments, exercises, and traction.

1b Findings: NLC image shows Tz C2-C7 of $5.2 \mathrm{~mm}$, ARA C2-C7 of -46.0, Tz C2-C3, Tz C3-C4, and Tz C5-C6 measurements of $-0.9 \mathrm{~mm},-0.3 \mathrm{~mm}$, and $0.4 \mathrm{~mm}$, respectively. Tz SCD at C2-C3, C3-C4, and C5-C6 measure 18, 16, and 17 mm, respectively. Technique: $30 \mathrm{mAs}, 200 \mathrm{~mA}, 76 \mathrm{kVp}, 72$ " FFD, CR at C4. 


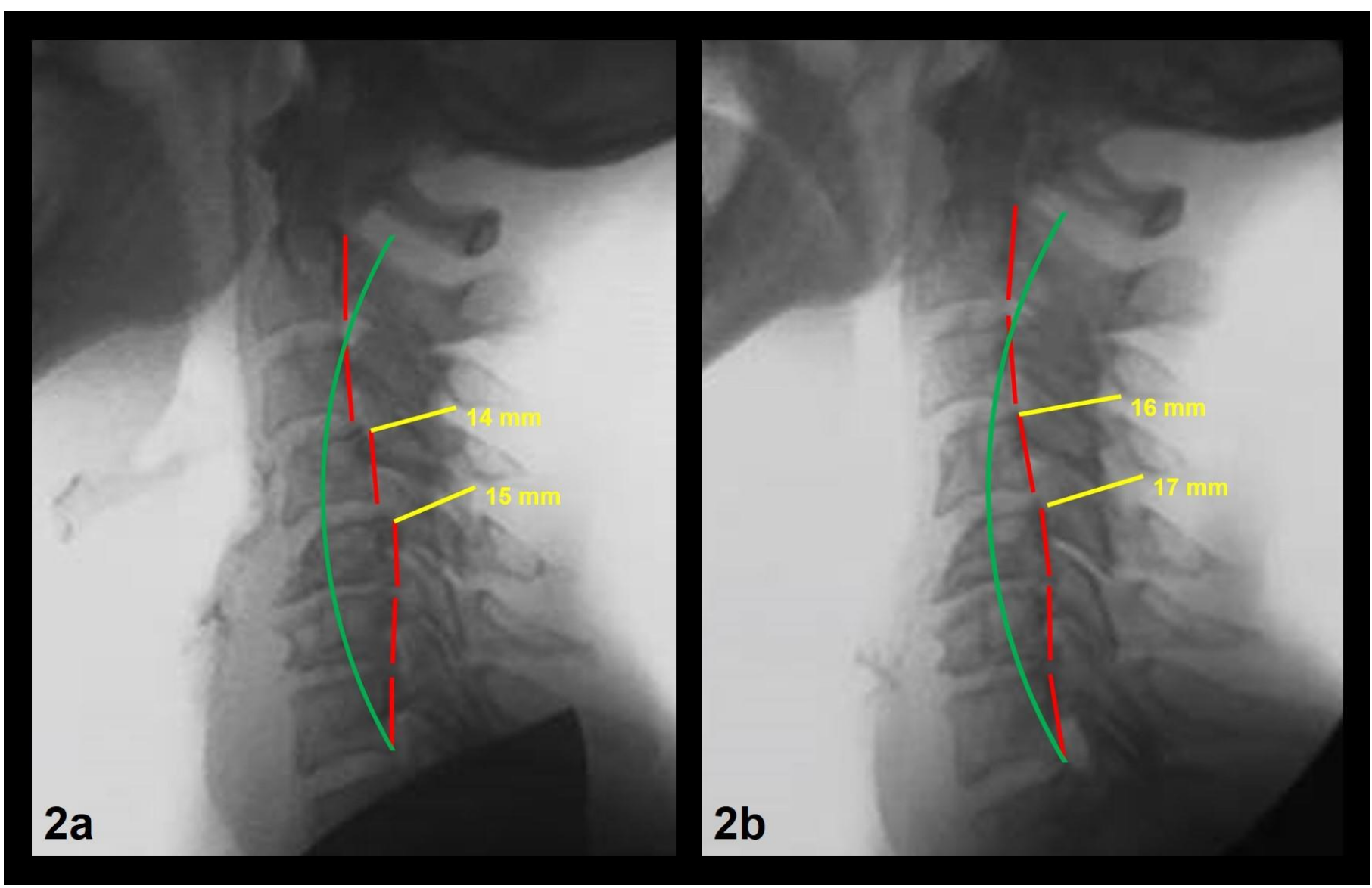

Figure 2: 67-year-old female with NP, bilateral upper trapezii pain, neck stiffness, restricted cervical ROM, cervical radicular symptoms, and a history of motor vehicle collision trauma.

Image Features: The green line represents a normal, ideal cervical alignment. The red line represents the actual posterior tangent lines of the C2-C7 vertebrae. The yellow line and text represent the spinal canal diameters and measurements at spondylolisthesis locations.

Figure 2a Patient 2 Pre-Treatment NLC Radiograph

2a Findings: NLC image shows Tz C2-C7 of $8.7 \mathrm{~mm}$, ARA C2-C7 of $-3.5^{\circ}$, spondylolistheses at C3-C4 and C4-C5 with Tz measurements of $2.5 \mathrm{~mm}$, and $4.4 \mathrm{~mm}$, respectively. Tz SCD at C3 -C4 and C4-C5 measure $14 \mathrm{~mm}$ and $15 \mathrm{~mm}$, respectively. Technique: $30 \mathrm{mAs}, 200 \mathrm{~mA}, 76 \mathrm{kVp}, 72 " \mathrm{FFD}, \mathrm{CR}$ at C4.

Figure 2b Patient 2 Post-Treatment NLC Radiograph

Intervention: Chiropractic BioPhysics ${ }^{\circledR}$ Mirror Image ${ }^{\circledR}$ spinal adjustments, exercises, and traction.

2b Findings: NLC image shows Tz C2-C7 of $7.8 \mathrm{~mm}$, ARA C2-C7 of -19.3, Tz C3-C4 and Tz C4-C5 measurements of 0.1 mm, and $1.1 \mathrm{~mm}$, respectively. Tz SCD at C3 -C4 and C4-C5 measure $16 \mathrm{~mm}$ and $17 \mathrm{~mm}$, respectively.

Technique: $30 \mathrm{mAs}, 200 \mathrm{~mA}, 76 \mathrm{kVp}, 72$ " FFD, CR at C4. 


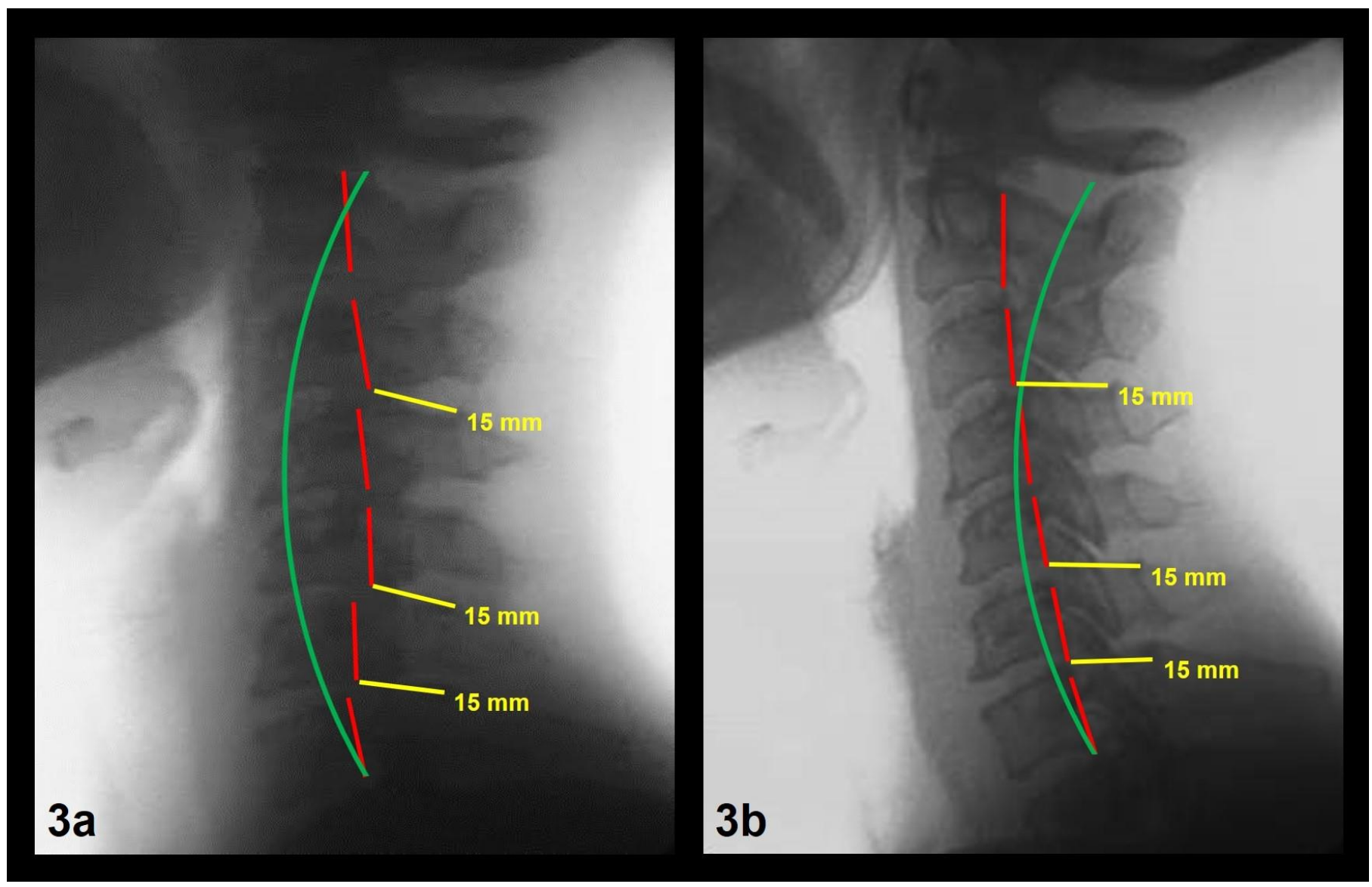

Figure 3: 53-year-old female with NP, bilateral upper trapezii pain, neck stiffness, restricted cervical ROM, cervical radicular symptoms, and a history of motor vehicle collision trauma.

Image Features: The green line represents a normal, ideal cervical alignment. The red line represents the actual posterior tangent lines of the $\mathrm{C} 2-\mathrm{C} 7$ vertebrae. The yellow line and text represent the spinal canal diameters and measurements at spondylolisthesis locations.

Figure 3a Patient 3 Pre-Treatment NLC Radiograph

3a Findings: NLC image shows Tz C2-C7 of $2.6 \mathrm{~mm}$, ARA C2-C7 of -6.1 ${ }^{\circ}$, spondylolistheses at C3-C4, C5-C6, and C6-C7 with Tz measurements of $-2.1 \mathrm{~mm},-4.3 \mathrm{~mm}$, and $-2.0 \mathrm{~mm}$, respectively. Tz SCD at C3-C4, C5-C6, and C6-C7 measure $15 \mathrm{~mm}, 15$ $\mathrm{mm}$, and $15 \mathrm{~mm}$, respectively.

Technique: $30 \mathrm{mAs}, 200 \mathrm{~mA}, 76 \mathrm{kVp}, 72 " \mathrm{FFD}, \mathrm{CR}$ at C4.

Figure 3b Patient 3 Post-Treatment NLC Radiograph

Intervention: Chiropractic BioPhysics ${ }^{\circledR}$ Mirror Image ${ }^{\circledR}$ spinal adjustments, exercises, and traction.

3b Findings: NLC image shows Tz C2-C7 of $10.7 \mathrm{~mm}$, ARA C2-C7 of $-16.8^{\circ}, \mathrm{Tz} \mathrm{C} 3-\mathrm{C} 4, \mathrm{Tz} \mathrm{C} 5-\mathrm{C} 6$, and $\mathrm{Tz} \mathrm{C} 6-\mathrm{C} 7$ measurements of $-0.5 \mathrm{~mm},-0.6 \mathrm{~mm}$, and $-0.5 \mathrm{~mm}$, respectively. Tz SCD at C3-C4, C5-C6, and C6-C7 measure $17 \mathrm{~mm}, 18 \mathrm{~mm}$, and $16 \mathrm{~mm}$, respectively.

Technique: 30 mAs, $200 \mathrm{~mA}, 76 \mathrm{kVp}, 72 " \mathrm{FFD}, \mathrm{CR}$ at C4. 


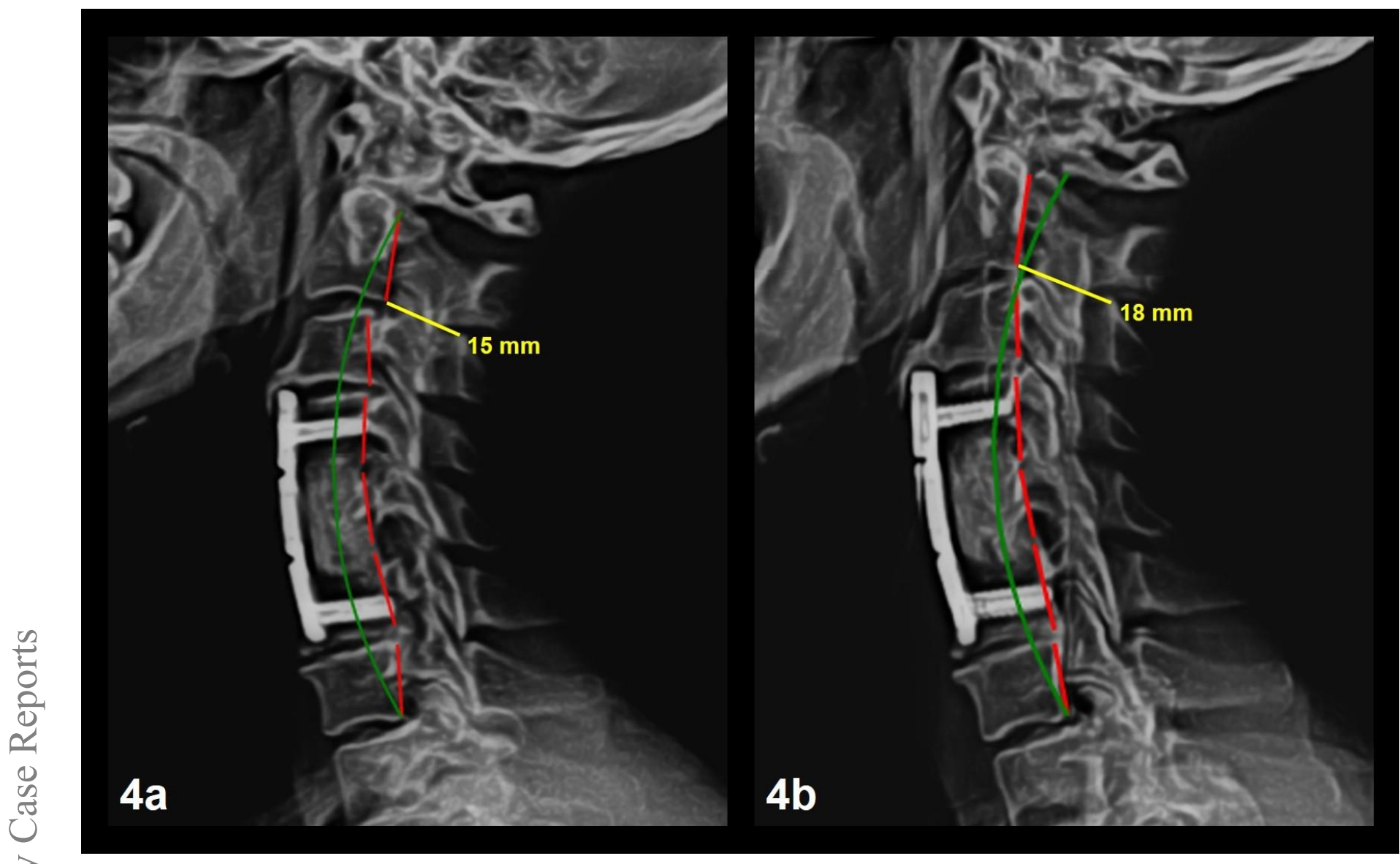

Figure 4: 46-year-old female with NP, bilateral upper trapezii pain, neck stiffness, restricted cervical ROM, cervical radicular symptoms, and a history of motor vehicle collision trauma.

Image Features: The green line represents a normal, ideal cervical alignment. The red line represents the actual posterior tangent lines of the C2-C7 vertebrae. The yellow line and text represent the spinal canal diameters and measurements at spondylolisthesis locations.

Figure 4a Patient 4 Pre-Treatment NLC Radiograph

4a Findings: NLC image shows anterior surgical fusion of C4-C6, Tz C2-C7 of $1.5 \mathrm{~mm}, \mathrm{ARA}$ C2-C7 of -12.4 ${ }^{\circ}$, spondylolisthesis at C2-C3 with a Tz measurement of $-4.5 \mathrm{~mm}$. Tz SCD at C2-C3 measures $15 \mathrm{~mm}$.

Technique: $30 \mathrm{mAs}, 200 \mathrm{~mA}, 76 \mathrm{kVp}, 72 " \mathrm{FFD}, \mathrm{CR}$ at C4.

Figure 4b Patient 4 Post-Treatment NLC Radiograph

Intervention: Chiropractic BioPhysics ${ }^{\circledR}$ Mirror Image ${ }^{\circledR}$ spinal adjustments, exercises, and traction.

4b Findings: NLC image shows anterior surgical fusion at C4-C6, Tz C2-C7 of $7.4 \mathrm{~mm}, \mathrm{ARA} \mathrm{C} 2-\mathrm{C} 7 \mathrm{of}-19.1^{\circ}, \mathrm{Tz} \mathrm{C} 2-\mathrm{C} 3$ measurement of $-0.8 \mathrm{~mm}$. Tz SCD at C2-C3 measures $18 \mathrm{~mm}$.

Technique: $30 \mathrm{mAs}, 200 \mathrm{~mA}, 76 \mathrm{kVp}, 72 " \mathrm{FFD}, \mathrm{CR}$ at C4. 


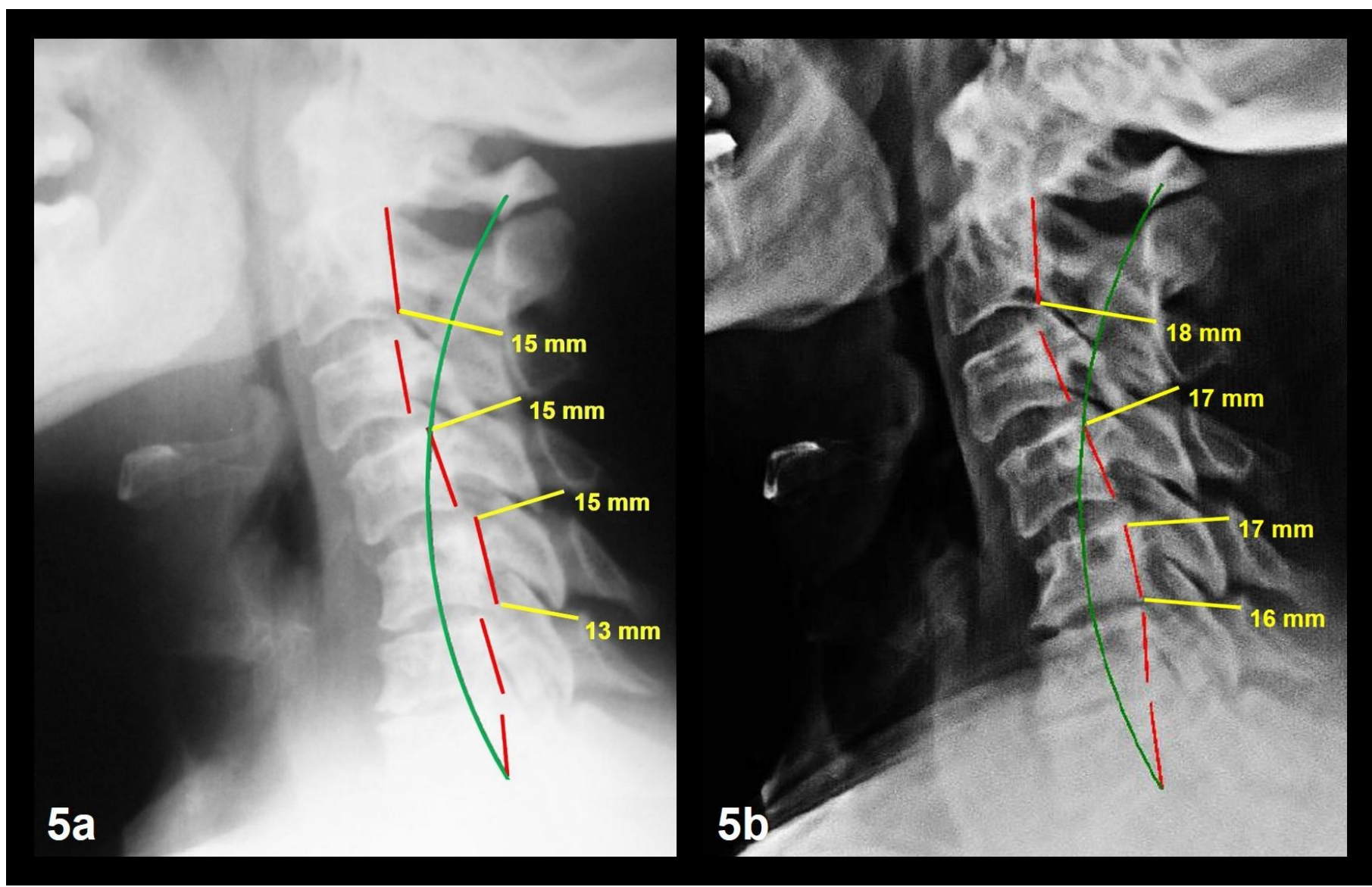

Figure 5: 51-year-old female with NP, bilateral upper trapezii pain, neck stiffness, restricted cervical ROM, cervical radicular symptoms, and a history of motor vehicle collision trauma.

Image Features: The green line represents a normal, ideal cervical alignment. The red line represents the actual posterior tangent lines of the C2-C7 vertebrae. The yellow line and text represent the spinal canal diameters and measurements at spondylolisthesis locations.

Figure 5a Patient 5 Pre-Treatment NLC Radiograph

5a Findings: NLC image shows Tz C2-C7 of $27.3 \mathrm{~mm}$, ARA C2-C7 of 2.4 ${ }^{\circ}$, spondylolistheses at C2-C3, C3-C4, C4-C5, and C5C6 with Tz measurements of $-3.0 \mathrm{~mm}, 3.1 \mathrm{~mm}, 4.2 \mathrm{~mm}$, and $-4.1 \mathrm{~mm}$, respectively. Tz SCD at C2-C3, C3-C4, C4-C5, and C5C6 measure $15 \mathrm{~mm}, 15 \mathrm{~mm}, 15 \mathrm{~mm}$, and $13 \mathrm{~mm}$, respectively.

Technique: $30 \mathrm{mAs}, 200 \mathrm{~mA}, 76 \mathrm{kVp}, 72 " \mathrm{FFD}, \mathrm{CR}$ at C4.

Figure 5b Patient 5 Post-Treatment NLC Radiograph

Intervention: Chiropractic BioPhysics ${ }^{\circledR}$ Mirror Image ${ }^{\circledR}$ spinal adjustments, exercises, and traction.

5b Findings: NLC image shows Tz C2-C7 of $21.9 \mathrm{~mm}$, ARA C2-C7 of -4.4 , Tz C2-C3, Tz C3-C4, Tz C4-C5, and Tz C5-C6 measurements of $-1.7 \mathrm{~mm}, 0.0 \mathrm{~mm}, 0.4 \mathrm{~mm}$, and $-0.2 \mathrm{~mm}$, respectively. Tz SCD at C2-C3, C3-C4, C4-C5, and C5-C6 measure $18 \mathrm{~mm}, 17 \mathrm{~mm}, 17 \mathrm{~mm}$, and $16 \mathrm{~mm}$, respectively.

Technique: $30 \mathrm{mAs}, 200 \mathrm{~mA}, 76 \mathrm{kVp}, 72 " \mathrm{FFD}, \mathrm{CR}$ at C4. 


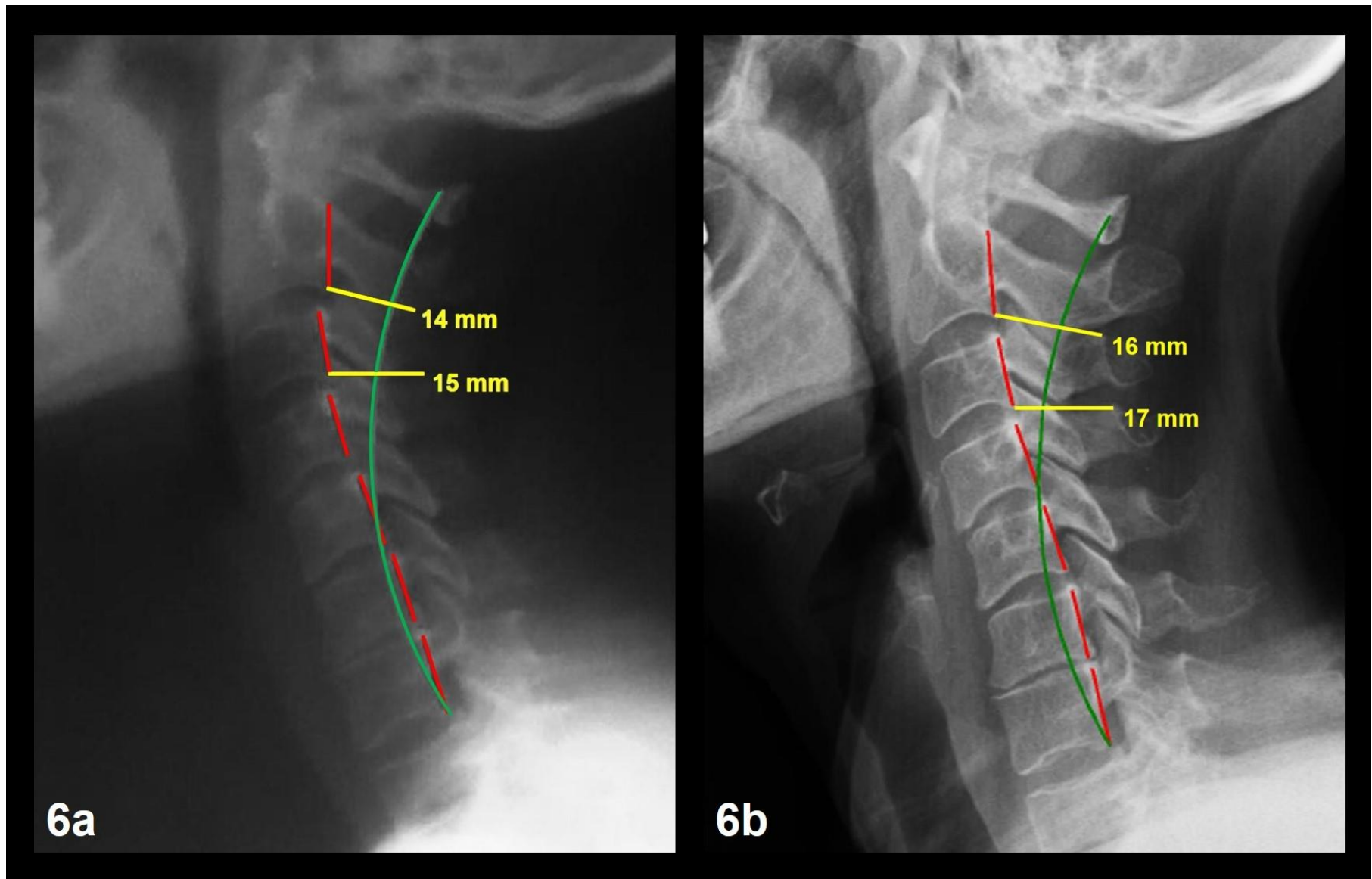

Figure 6: 58-year-old female with NP, bilateral upper trapezii pain, neck stiffness, restricted cervical ROM, cervical radicular symptoms, and a history of motor vehicle collision trauma.

Image Features: The green line represents a normal, ideal cervical alignment. The red line represents the actual posterior tangent lines of the C2-C7 vertebrae. The yellow line and text represent the spinal canal diameters and measurements at spondylolisthesis locations.

Figure 6a Patient 6 Pre-Treatment NLC Radiograph 6a Findings: NLC image shows Tz C2-C7 of $23.4 \mathrm{~mm}$, ARA C2-C7 of $-11.7^{\circ}$, spondylolistheses at C2-C3 and C3-C4 with Tz measurements of $-2.7 \mathrm{~mm}$ and $-2.0 \mathrm{~mm}$, respectively. Tz SCD at C2-C3 and C3-C4 measure $14 \mathrm{~mm}$ and $15 \mathrm{~mm}$, respectively. Technique: $30 \mathrm{mAs}, 200 \mathrm{~mA}, 76 \mathrm{kVp}, 72 " \mathrm{FFD}, \mathrm{CR}$ at C4.

Figure 6b Patient 6 Post-Treatment NLC Radiograph Intervention: Chiropractic BioPhysics ${ }^{\circledR}$ Mirror Image ${ }^{\circledR}$ spinal adjustments, exercises, and traction. 6b Findings: NLC image shows Tz C2-C7 of $23.8 \mathrm{~mm}$, ARA C2-C7 of $-11.8^{\circ}$, Tz C2-C3 and Tz C3-C4 measurements of $0.2 \mathrm{~mm}$ and $-0.7 \mathrm{~mm}$, respectively. Tz SCD at C2-C3 and C3-C4 measure $16 \mathrm{~mm}$ and $17 \mathrm{~mm}$, respectively.

Technique: $30 \mathrm{mAs}, 200 \mathrm{~mA}, 76 \mathrm{kVp}, 72$ " FFD, CR at C4. 


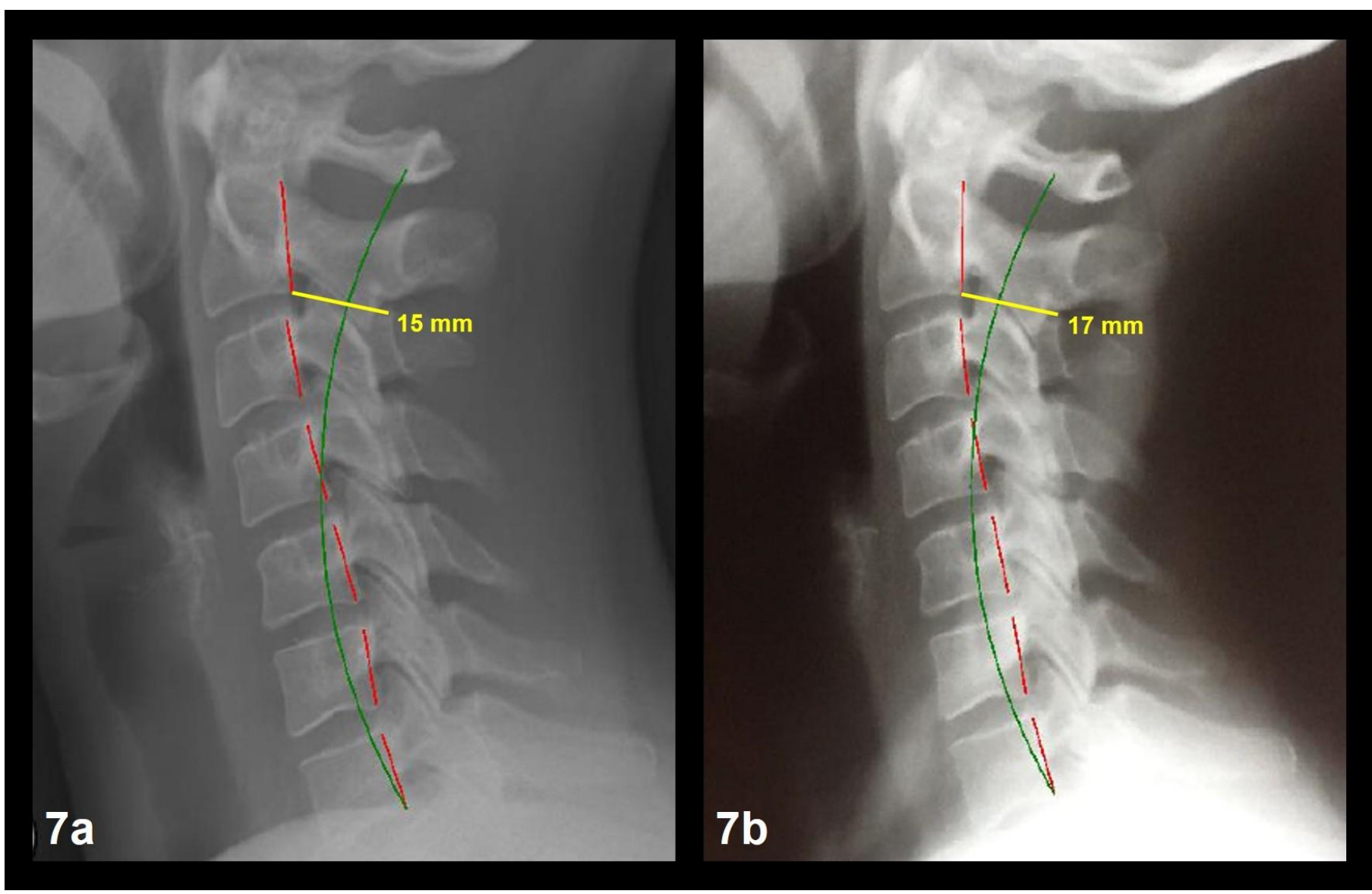

Figure 7: 36-year-old female with NP, bilateral upper trapezii pain, neck stiffness, restricted cervical ROM, cervical radicular symptoms, and a history of motor vehicle collision trauma.

Image Features: The green line represents a normal, ideal cervical alignment. The red line represents the actual posterior tangent lines of the $\mathrm{C} 2-\mathrm{C} 7$ vertebrae. The yellow line and text represent the spinal canal diameters and measurements at spondylolisthesis locations.

Figure 7a Patient 7 Pre-Treatment NLC Radiograph

7a Findings: NLC image shows Tz C2-C7 of $24.3 \mathrm{~mm}$, ARA C2-C7 of $-12.7^{\circ}$, spondylolisthesis at $\mathrm{C} 2-\mathrm{C} 3$ with a Tz measurement of $-2.2 \mathrm{~mm}$. Tz SCD at C2-C3 measures $15 \mathrm{~mm}$.

Technique: $30 \mathrm{mAs}, 200 \mathrm{~mA}, 76 \mathrm{kVp}, 72 " \mathrm{FFD}, \mathrm{CR}$ at C4.

Figure 7b Patient 7 Post-Treatment NLC Radiograph

Intervention: Chiropractic BioPhysics ${ }^{\circledR}$ Mirror Image ${ }^{\circledR}$ spinal adjustments, exercises, and traction.

7b Findings: NLC image shows Tz C2-C7 of $19.1 \mathrm{~mm}$, ARA C2-C7 of $-17.1^{\circ}$, Tz C2-C3 with a measurement of $-0.5 \mathrm{~mm}$. Tz $\mathrm{SCD}$ at $\mathrm{C} 2-\mathrm{C} 3$ measures $17 \mathrm{~mm}$.

Technique: $30 \mathrm{mAs}, 200 \mathrm{~mA}, 76 \mathrm{kVp}, 72$ " FFD, CR at C4. 


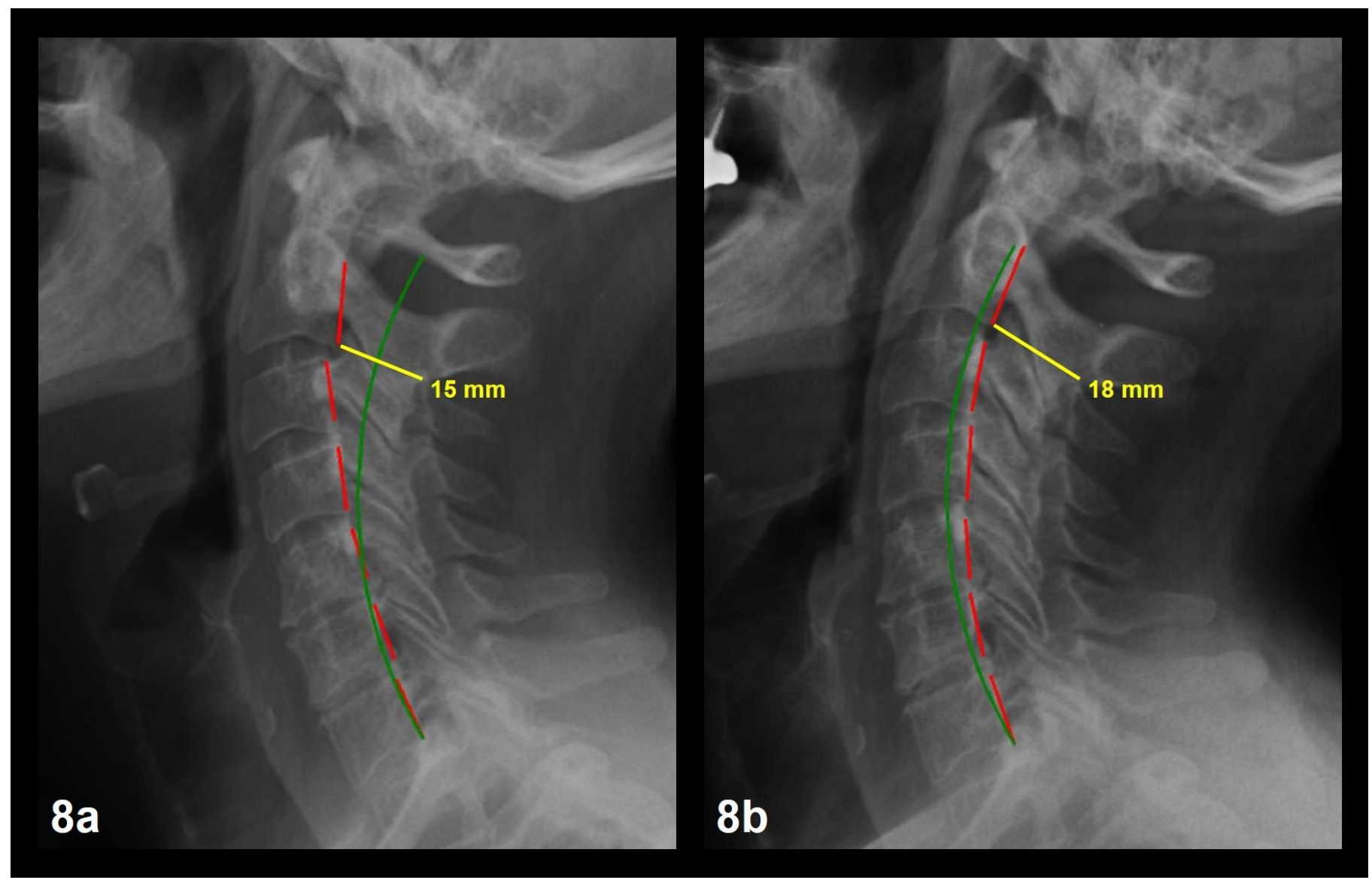

Figure 8: 53-year-old female with NP, bilateral upper trapezii pain, neck stiffness, restricted cervical ROM, cervical radicular symptoms, and a history of motor vehicle collision trauma.

Image Features: The green line represents a normal, ideal cervical alignment. The red line represents the actual posterior tangent lines of the $\mathrm{C} 2-\mathrm{C} 7$ vertebrae. The yellow line and text represent the spinal canal diameters and measurements at spondylolisthesis locations.

Figure 8a Patient 8 Pre-Treatment NLC Radiograph

8a Findings: NLC image shows Tz C2-C7 of $15.5 \mathrm{~mm}$, ARA C2-C7 of $-29.3^{\circ}$, spondylolisthesis at C2-C3 with a Tz measurement of $-3.1 \mathrm{~mm}$. Tz SCD at C2-C3 measures $15 \mathrm{~mm}$.

Technique: $30 \mathrm{mAs}, 200 \mathrm{~mA}, 76 \mathrm{kVp}, 72 " \mathrm{FFD}, \mathrm{CR}$ at C4.

Figure 8b Patient 8 Post-Treatment NLC Radiograph

Intervention: Chiropractic BioPhysics ${ }^{\circledR}$ Mirror Image ${ }^{\circledR}$ spinal adjustments, exercises, and traction.

8b Findings: NLC image shows Tz C2-C7 of $-1.8 \mathrm{~mm}$, ARA C2-C7 of $-42.0^{\circ}, \mathrm{Tz} \mathrm{C} 2-\mathrm{C} 3$ with a measurement of $-0.3 \mathrm{~mm}$. Tz $\mathrm{SCD}$ at C2-C3 measures $18 \mathrm{~mm}$.

Technique: $30 \mathrm{mAs}, 200 \mathrm{~mA}, 76 \mathrm{kVp}, 72$ " FFD, CR at C4. 


\begin{tabular}{|l|l|l|l|l|}
\hline Measurement & Normal & Pre-treatment Mean & Post-treatment Mean & Mean Difference \\
\hline ARA C2-C7 $\left(^{\circ}\right)$ & -42.0 & $-15.5 \pm 15.8$ & $-22.1 \pm 13.5$ & 6.6 \\
\hline Tz C2-C7 $(\mathbf{m m})$ & 0.0 & $15.1 \pm 13.9$ & $11.8 \pm 8.4$ & 3.3 \\
\hline Tz DCS (mm) & 0.0 & $3.1 \pm 0.9$ & $0.5 \pm 0.4$ & 2.6 \\
\hline Tz SCD at DCS (mm) & 17.0 & $14.8 \pm 0.6$ & $17.0 \pm 0.8$ & 2.2 \\
\hline NDI (\%) & 0.0 & $34.5 \pm 5.7$ & $4.3 \pm 1.2$ & 30.2 \\
\hline
\end{tabular}

Table 1: Comparison evaluation of pre-treatment* and post-treatment* clinical findings

*Treatment is 30 sessions of Mirror Image ${ }^{\circledR}$ spinal exercises, adjustments, and traction over 12 weeks per Chiropractic BioPhysics ${ }^{\circledR}$ protocols explained in the subsection, Interventions and Outcomes, of the Case Descriptions section.

ARA = Absolute Rotational Angle of Measurement

$\mathrm{Tz}=$ Translation in the z-axis/sagittal plane

DCS $=$ Degenerative Cervical Spondylolisthesis

$\mathrm{SCD}=$ Spinal Canal Diameter

NDI $=$ Neck Disability Index

Xray $1=$ Pre-treatment values

Xray 2 = Post-treatment values following 30 sessions over 12 weeks

Description: Table 1 shows mean values of eight patients for absolute rotational angle from $\mathrm{C} 2$ to $\mathrm{C} 7$, translations in the $\mathrm{z}$-axis (Tz) of the cervical region from $\mathrm{C} 2-\mathrm{C} 7$ and per degenerative cervical spondylolisthesis segments, and neck disability index scores of pre-treatment and post-treatment assessments. Mean ARA C2-C7 improved from $-15.5^{\circ}$ to $-22.1^{\circ}$ (normal is $-42.0^{\circ}$ ); mean Tz C2-C7 improved from $28.0 \mathrm{~mm}$ to $11.8 \mathrm{~mm}$ (normal is $0.0 \mathrm{~mm}$ ); mean Tz DCS improved from $3.1 \mathrm{~mm}$ to $0.9 \mathrm{~mm}$ (normal is < $1.0 \mathrm{~mm}$ ); mean Tz SCD at DCS improved from $14.8 \mathrm{~mm}$ to $17.0 \mathrm{~mm}$ (normal is $17 \mathrm{~mm}$ ); and mean NDI improved from $34.5 \%$ to $4.3 \%$ (normal is $0 \%$ ). All measurements improved toward normal values.

\begin{tabular}{|c|c|}
\hline Spondylolisthesis & Summary \\
\hline Etiology & $\begin{array}{l}\text { - Translation of vertebra with respect to vertebra below } \\
\text { - Abnormal weight distribution, soft tissue laxity, and instability } \\
\text { - Excessive joint play and degeneration of the IVD } \\
\text { - Abnormal spinal alignment and positional loading of the cervical spine } \\
\text { - May present with neck pain, radiculopathy, or no symptoms }\end{array}$ \\
\hline Incidence & - 5.2 to $11 \%$ \\
\hline Gender Ratio & - Male:Female is $1.5: 1$ in grade 1 and $2.2: 1$ in grade 2 spondylolisthesis. \\
\hline Age Predilection & $\begin{array}{l}\text { - Increase in prevalence after } 60 \text { years } \\
\text { - } 33.3 \% \text { of } 20-59 \text {-years-olds; } 66.7 \% \text { of } 60-99 \text {-years-olds }\end{array}$ \\
\hline Risk Factors & $\begin{array}{l}\text { - Increased age, sex, facet hypertrophy, cervical hypolordosis/kyphosis, anterior head translation, } \\
\text { cervical spondylosis/degeneration, history of cervical spine surgery } \\
\text { - Abnormal spinal alignment } \\
\text { - Correlation with cervicothoracic sagittal alignment factors }\end{array}$ \\
\hline Treatment & $\begin{array}{l}\text { - Spinal fusion surgery to stabilize } \\
\text { - Non-surgical methods include active physical therapy, education or counseling for exercising, } \\
\text { nonsteroidal anti-inflammatory drugs, homeopathic remedies, soft tissue massage, trigger point } \\
\text { therapy, spinal mobilization techniques to restricted areas, cryotherapy, and chiropractic }\end{array}$ \\
\hline Prognosis & - Degenerative condition unless the spine is stabilized \\
\hline Findings on Imaging & $\begin{array}{l}\text { - Most common levels are } \mathrm{C} 3-\mathrm{C} 4, \mathrm{C} 4-5 \text {, and } \mathrm{C} 5-\mathrm{C} 6 \text { followed by } \mathrm{C} 6-\mathrm{C} 7 \\
\text { - Radiograph imaging shows extent of segmental translation } \\
\text { - MRI shows extent of soft tissue damage }\end{array}$ \\
\hline
\end{tabular}

Table 2: Summary table of cervical spondylolisthesis in the sagittal plane 


\begin{tabular}{|c|c|c|c|c|}
\hline $\begin{array}{l}\text { Differential } \\
\text { Diagnoses }\end{array}$ & Plain Radiography & $\begin{array}{l}\text { Magnetic Resonance } \\
\text { Imaging }\end{array}$ & $\begin{array}{l}\text { Computed Tomography } \\
\text { Myelography }\end{array}$ & $\begin{array}{l}\text { Computed } \\
\text { Tomography }\end{array}$ \\
\hline $\begin{array}{l}\text { Degenerative } \\
\text { Cervical } \\
\text { Spondylolisthesis }\end{array}$ & $\begin{array}{l}\text { - Upright, weight-bearing } \\
\text { lateral cervical view is most } \\
\text { appropriate for detecting } \\
\text { anterior and posterior } \\
\text { vertebral segmental } \\
\text { translation. } \\
\text { - Lateral cervical flexion and } \\
\text { extension views demonstrate } \\
\text { changes in vertebral segmental } \\
\text { translation during motion } \\
\text { indicating cervical instability. }\end{array}$ & $\begin{array}{l}\text { Most appropriate for } \\
\text { imaging spinal stenosis } \\
\text { or facet joint } \\
\text { arthropathy. } \\
\text { - Provides a detailed } \\
\text { view of the cervical } \\
\text { spine, spinal canal, } \\
\text { spinal cord, and soft } \\
\text { tissue structures } \\
\text { affected by } \\
\text { spondylolisthesis. }\end{array}$ & $\begin{array}{l}\text { Useful in assessing } \\
\text { spinal stenosis or nerve } \\
\text { roots and when MRI is } \\
\text { contraindicated or } \\
\text { inconclusive. } \\
\text { - Provides a view of the } \\
\text { entire cervical spine and } \\
\text { is done in the standing } \\
\text { position (accentuates } \\
\text { spinal stenosis). }\end{array}$ & $\begin{array}{l}\text { - Useful when MRI and } \\
\text { CT myelography are } \\
\text { contraindicated or } \\
\text { inconclusive. } \\
\text { - Useful in assessing } \\
\text { spinal stenosis or nerve } \\
\text { roots and provides a } \\
\text { detailed view of the } \\
\text { facet joints. }\end{array}$ \\
\hline Cervical Fracture & $\begin{array}{l}\text { - Upright, weight-bearing } \\
\text { lateral cervical view is most } \\
\text { appropriate for detecting } \\
\text { anterior and posterior } \\
\text { vertebral segmental translation } \\
\text { - Lateral cervical flexion and } \\
\text { extension views demonstrate } \\
\text { changes in vertebral segmental } \\
\text { translation during motion } \\
\text { indicating cervical instability. } \\
\text { - Oblique cervical views are } \\
\text { most appropriate for detecting }\end{array}$ & & & \\
\hline $\begin{array}{l}\text { Cervical Canal } \\
\text { Stenosis }\end{array}$ & & $\begin{array}{l}\text { Most appropriate for } \\
\text { imaging spinal } \\
\text { stenosis. } \\
\text { - Provides a detailed } \\
\text { view of the cervical } \\
\text { spine, spinal canal, } \\
\text { spinal cord, and soft } \\
\text { tissue structures. }\end{array}$ & $\begin{array}{l}\text { Useful in assessing } \\
\text { spinal stenosis or nerve } \\
\text { roots and when MRI is } \\
\text { contraindicated or } \\
\text { inconclusive. } \\
\text { Provides a view of the } \\
\text { entire cervical spine and } \\
\text { is done in the standing } \\
\text { position (accentuates } \\
\text { spinal stenosis). }\end{array}$ & $\begin{array}{l}\text { - Useful when MRI and } \\
\text { CT myelography are } \\
\text { contraindicated or } \\
\text { inconclusive. } \\
\text { - Useful in assessing } \\
\text { spinal stenosis or nerve } \\
\text { roots and provides a } \\
\text { detailed view of the } \\
\text { facet joints. }\end{array}$ \\
\hline $\begin{array}{l}\text { Cervical Disc } \\
\text { Degeneration }\end{array}$ & & $\begin{array}{l}\text { Provides a detailed } \\
\text { view of the cervical } \\
\text { spine, spinal cord, and } \\
\text { soft tissue structures, } \\
\text { including the } \\
\text { intervertebral discs and } \\
\text { any degeneration. }\end{array}$ & & \\
\hline $\begin{array}{l}\text { Cervical Facet } \\
\text { Dislocation }\end{array}$ & $\begin{array}{l}\text { - Upright, weight-bearing } \\
\text { lateral cervical view is most } \\
\text { appropriate for detecting } \\
\text { anterior and posterior } \\
\text { vertebral segmental translation } \\
\text { and vertebral body and } \\
\text { spinous process fractures. } \\
\text { - Anteroposterior views } \\
\text { demonstrate cervical articular } \\
\text { pillar fractures. }\end{array}$ & & & \\
\hline $\begin{array}{l}\text { Cervical Facet } \\
\text { Arthropathy }\end{array}$ & & $\begin{array}{l}\text { - Most appropriate for } \\
\text { imaging spinal stenosis } \\
\text { or facet joint } \\
\text { arthropathy. } \\
\text { - Provides a detailed } \\
\text { view of the cervical } \\
\text { spine, spinal cord, } \\
\text { facet joints, and } \\
\text { corresponding soft } \\
\text { tissue structures. }\end{array}$ & & $\begin{array}{l}\text { - Useful when MRI and } \\
\text { CT myelography are } \\
\text { contraindicated or } \\
\text { inconclusive. } \\
\text { - Useful in assessing } \\
\text { spinal stenosis or nerve } \\
\text { roots and provides a } \\
\text { detailed view of the } \\
\text { facet joints. }\end{array}$ \\
\hline
\end{tabular}

Table 3: Differential diagnosis table for cervical spondylolisthesis in the sagittal plane and appropriate imaging 


\section{ABBREVIATIONS}

ADL - Activity of Daily Living

AP - Anterioposterior

ARA - Absolute Rotational Angle

ARA C2-C7 - Absolute Rotational Angle from C2 to C7

C2 - Second Cervical Vertebra

C7 - Seventh Cervical Vertebra

CBP® - Chiropractic BioPhysics®

CNS - Central Nervous System

CR - Central Ray

CT - Computed Tomography

DCS - Degenerative Cervical Spondylolisthesis

EMR - Electronic Medical Records

FFD - Film Focal Distance

$\mathrm{kVp}$ - kilovoltage peak

$\mathrm{mA}$ - milliampere

mAs - milliampere second

mm - millimeter

MRI - Magnetic Resonance Imaging

MVC - Motor Vehicle Collision

NDI - Neck Disability Index

NLC - Neutral Lateral Cervical

NP - Neck Pain

ROM - Range of Motion

-RxH - Extension of the Head

SCD - Spinal Canal Diameter

Spinal Alignment Shorthand

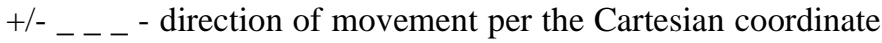
systsem

$\mathrm{T}_{-}$- $_{-}$Translation along an axis per the Cartesian coordinate system

$\mathrm{R}_{\text {_ _ }}$ - Rotation around an axis per the Cartesian coordinate system

_ $\mathrm{X}_{-}-\mathrm{X}$-axis (in the body's frontal plane) per the Cartesian coordinate system

_y_ - y-axis (in the body's sagittal plane) per the Cartesian coordinate system

_ $z_{-}$- z-axis (in the body's transverse plane) per the Cartesian coordinate system

- $\mathrm{P}$ - Pelvis (in relation to the feet)

- $\mathrm{T}$ - Thoracic cage (in relation to the pelvis)

_- $\mathrm{H}$ - Head (in relation to the thoracic cage)

Spine Segment Shorthand

C_ - Cervical Region (7 vertebrae)

$\mathrm{T}_{\text {_ }}$ - Thoracic Region (12 vertebrae)

$\mathrm{L}_{-}$- Lumbar Region (5 vertebrae)

$\mathrm{S}_{-}$- Sacral Region (4 vertebrae)

\# - the number of the vertebra in the spinal region numbered from superior to inferior

T4 - Fourth Thoracic Vertebra

$\mathrm{Tz}$ - Translation in the $\mathrm{z}$-axis/sagittal plane

$+\mathrm{TzH}$ - Anterior Translation of the Head

-TzH - Posterior Translation of the Head

UTS - Universal Tractioning System

\section{KEYWORDS}

chiropractic; Chiropractic BioPhysics ; adjustment; CBP ; spinal instability; cervical spondylolisthesis; cervical spine; posture

\section{ACKNOWLEDGEMENTS}

The authors would like to acknowledge Chiropractic BioPhysics ${ }^{\circledR}$ NonProfit (a spine research foundation in Eagle, ID, USA) and the Institute for Spinal Health and Performance (a spine research institute in Cumming, GA, USA) for their support.

\section{Online access}

This publication is online available at:

www.radiologycases.com/index.php/radiologycases/article/view/3890

\section{Peer discussion}

Discuss this manuscript in our protected discussion forum at: www.radiolopolis.com/forums/JRCR

\section{Interactivity}

This publication is available as an interactive article with scroll, window/level, magnify and more features. Available online at www.RadiologyCases.com

Published by EduRad

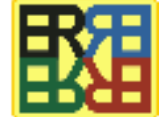

www.EduRad.org 